\title{
Patterns in the distribution of avian lice (Phthiraptera: Amblycera, Ischnocera)
}

\author{
József Rékási, Lajos Rózsa and Botond J. Kiss
}

Rékási, J., Rózsa, L. and Kiss, B. J. 1997. Patterns in the distribution of avian lice (Phthiraptera: Amblycera, Ischnocera). - J. Avian Biol. 28: 150-156.

\begin{abstract}
The frequency distributions of 15 species of avian lice among individuals within host populations are described and 12 previously described distributions are reviewed. All of these distributions were aggregated, but some of them do not conform to the negative binomial model ( 4 at $\mathrm{P}<0.05$ out of the 25 examined). Distribution measures (prevalence, mean and variance of louse subpopulations, the exponent $k$ of the negative binomial distribution, and the index of discrepancy) of lice of colonial birds are compared to those of territorial ones. Minimum sample size requirement is calculated for each case study. Louse subpopulation size and variance do not correlate with host social system, however, residuals from the log mean-log variance regression do. Lice of territorial hosts tend to form more variable subpopulations than those predicted by the regression curve, while those of colonial birds tend to form less variable subpopulations. Prevalence and $k$ are higher, while the index of discrepancy is lower, for the distributions of lice of colonial hosts, indicating less aggregated louse distributions compared to those of territorial host species.
\end{abstract}

J. Rékási, Benedictiner School, H-9090 Pannonhalma, Hungary. L. Rózsa (correspondence), Department of Parasitology and Zoology, University of Veterinary Science, $H$-1400 Budapest, P.O. Box 2, Hungary.E-mail: lrozsa@ns.univet.hu. B. J. Kiss, 8800 Tulcea, Op. 4, P.O. Box 13, Romania.

An aggregated distribution is a general feature of the occurrence of parasites within their host populations: many hosts have few if any parasites, while a few have a lot of them. This phenomenon is also referred to as a contagious or clumped distribution. Its causes and consequences have been studied extensively in many taxa of parasites. Following Crofton (1971) the negative binomial distribution is widely used as a mathematical model to describe this pattern. Here we provide data on 15 new and 12 previously published case studies describing the distribution patterns of avian lice (Phthiraptera: Amblycera, Ischnocera) within their host populations.

Host sociality is known to affect host-parasite interactions. Case studies on avian ectoparasites, including nest-dwelling mites, ticks, bugs, fleas and flies, indicate that an increased level of ectoparasitism may be a cost of social life (Brown and Brown 1986, Møller 1987, Shields and Crook 1987, Duffy 1991, Chapman and George 1991, Loye and Carroll 1991, Poiani 1992).
Unlike lice, these arthropods have free-ranging invasive forms capable of actively searching for new host individuals.

In contrast, avian lice are contagious ectoparasites as their transmission is highly dependent on direct bodyto-body contacts among hosts. In a comparison between lice of a territorial versus a colonial corvid species, louse subpopulations exhibited similar means, but tended to be more prevalent and less aggregated on the colonial host, suggesting that colonial breeding may facilitate horizontal transmission of avian lice (Rózsa et al. 1996). Feather mites, another group of contagious ectoparasites, also exhibited a higher prevalence on colonial bird species than on territorial ones (Poulin 1991).

To investigate whether the effect of host social behaviour can also be detected in the present data set we compare the distribution measures of the lice of colonial hosts (12 distributions) to those of territorial ones (15 distributions).

\footnotetext{
(c) JOURNAL OF AVIAN BIOLOGY
} 
Table 1. Observed distributions of 15 louse species collected from 5 host species. In each pair of rows the first one refers to the number of lice found on a bird (i.e. an infestation class) and the second row refers to the number of birds belonging to the class. Classes with no birds are not indicated.

\begin{tabular}{|c|c|c|c|c|c|c|c|c|c|c|c|c|c|c|c|c|c|c|c|c|c|c|}
\hline \multicolumn{23}{|l|}{ Anas platyrhynchos } \\
\hline \multirow[t]{2}{*}{ Anaticola crassicornis } & 0 & & & & 4 & 6 & 7 & 8 & 9 & 11 & 13 & 14 & 15 & 21 & 29 & 30 & 44 & 2363 & & & & \\
\hline & 33 & 5 & 5 & 4 & 3 & 3 & 1 & 3 & 2 & 2 & 1 & 4 & 1 & 1 & 1 & 1 & 1 & 1 & & & & \\
\hline \multirow[t]{2}{*}{ Anatoecus dentatus } & 0 & 1 & 2 & 3 & 5 & 6 & 15 & 16 & 17 & 20 & 75 & 83 & & & & & & & & & & \\
\hline & 57 & 2 & 3 & 2 & 1 & 1 & 1 & 1 & 1 & 1 & 1 & 1 & & & & & & & & & & \\
\hline \multirow[t]{2}{*}{ Anatoecus icterodes } & 0 & 1 & 2 & 3 & 6 & 8 & 9 & 10 & 549 & & & & & & & & & & & & & \\
\hline & 60 & 4 & 1 & 2 & 1 & 1 & 1 & 1 & 1 & & & & & & & & & & & & & \\
\hline \multirow[t]{2}{*}{ Trinoton querquedulae } & 0 & 1 & 2 & 3 & 4 & 6 & 7 & 44 & & & & & & & & & & & & & & \\
\hline & 63 & 3 & 1 & 1 & 1 & 1 & 1 & 1 & & & & & & & & & & & & & & \\
\hline \multirow[t]{2}{*}{ Trinoton luridum } & 0 & & 2 & 3 & 4 & & & & & & & & & & & & & & & & & \\
\hline & 63 & 3 & 3 & 2 & 1 & & & & & & & & & & & & & & & & & \\
\hline \multicolumn{23}{|l|}{ Scolopax rusticola } \\
\hline \multirow[t]{2}{*}{ Cummingsiella aurea } & 0 & 1 & & 3 & 4 & 5 & 7 & 8 & 9 & 10 & 13 & 14 & 15 & 16 & 29 & 30 & 38 & 40 & 66 & 68 & 75 & 276 \\
\hline & 67 & 3 & 3 & 1 & 5 & 5 & 1 & 1 & 2 & 2 & 1 & 1 & 1 & 1 & 1 & 1 & 1 & 1 & 1 & 1 & 1 & 1 \\
\hline \multirow[t]{2}{*}{ Rhynonirmus helvolus } & 0 & 1 & 2 & 3 & 4 & 8 & 9 & 13 & 19 & 24 & 34 & 685 & & & & & & & & & & \\
\hline & 82 & 2 & 1 & 2 & 3 & 2 & 2 & 2 & 2 & 1 & 2 & 1 & & & & & & & & & & \\
\hline \multicolumn{23}{|l|}{ Streptopelia decaocto } \\
\hline \multirow[t]{2}{*}{ Columbicola columbae bacillus } & 0 & 1 & 2 & 3 & 4 & 5 & 6 & 7 & 8 & 9 & 10 & 11 & 12 & 13 & 14 & 16 & 20 & 22 & 29 & 47 & & \\
\hline & 55 & 10 & 6 & 8 & 2 & 2 & 1 & 3 & 5 & 5 & 1 & 3 & 3 & 1 & 1 & 1 & 1 & 1 & 1 & 1 & & \\
\hline \multirow[t]{2}{*}{ Coloceras sofioticus } & 0 & 1 & 2 & 3 & 4 & 5 & 9 & 36 & & & & & & & & & & & & & & \\
\hline & 93 & 7 & 3 & 2 & 1 & 3 & 1 & 1 & & & & & & & & & & & & & & \\
\hline \multicolumn{23}{|l|}{ Corvus corone cornix } \\
\hline \multirow[t]{2}{*}{ Philopterus ocellatus } & 0 & 1 & 2 & 3 & 4 & 5 & 6 & 7 & 8 & 9 & 10 & 12 & 13 & 14 & 22 & 32 & 33 & 35 & 36 & 58 & & \\
\hline & 50 & 4 & 2 & 3 & 1 & 6 & 2 & 1 & 2 & 2 & 4 & 3 & 2 & 1 & 1 & 1 & 1 & 1 & 1 & 1 & & \\
\hline \multirow[t]{2}{*}{ Myrsidea cornicis } & 0 & 1 & 2 & 3 & 4 & 5 & 7 & 8 & 9 & 10 & 11 & 12 & 14 & 15 & 17 & 46 & 101 & & & & & \\
\hline & 60 & 5 & 1 & 2 & 1 & 2 & 3 & 3 & 1 & 1 & 3 & 1 & 2 & 1 & 1 & 1 & 1 & & & & & \\
\hline \multicolumn{23}{|l|}{ Corvus frugilegus } \\
\hline \multirow[t]{2}{*}{ Myrsidea isostoma } & 0 & 1 & 2 & 3 & 4 & 5 & 6 & 7 & 8 & 9 & 10 & 11 & 14 & 18 & 20 & 23 & 30 & 32 & 40 & 44 & 62 & 197 \\
\hline & 11 & 2 & 2 & 2 & 1 & 1 & 1 & 1 & 1 & 1 & 3 & 1 & 1 & 1 & 1 & 1 & 1 & 1 & 1 & 1 & 1 & 1 \\
\hline \multirow[t]{2}{*}{ Philopterus atratus } & 0 & 1 & 2 & 4 & 5 & 7 & 9 & 12 & 18 & 19 & 21 & 68 & 71 & 115 & 149 & & & & & & & \\
\hline & 13 & 3 & 4 & 2 & 1 & 2 & 2 & 2 & 2 & 1 & 1 & 1 & 1 & 1 & 1 & & & & & & & \\
\hline \multirow[t]{2}{*}{ Brueelia tasniamae } & 0 & 1 & 3 & 4 & 5 & 6 & 14 & 20 & 38 & 46 & 105 & 111 & 131 & 143 & & & & & & & & \\
\hline & 19 & 1 & 3 & 1 & 2 & 2 & 1 & 1 & 1 & 1 & 1 & 1 & 1 & 2 & & & & & & & & \\
\hline \multirow[t]{2}{*}{ Allocolpocephalum fregli } & 0 & 1 & 2 & 3 & 5 & 10 & 12 & & & & & & & & & & & & & & & \\
\hline & 28 & 3 & 1 & 2 & 1 & 1 & 1 & & & & & & & & & & & & & & & \\
\hline
\end{tabular}

Minimum sample size required to assess mean subpopulation size has never been published for avian lice. This is surprising since louse distributions may be remarkably aggregated and this feature may have a dramatic effect on sample-size requirements. Therefore we also present estimates of minimum sample sizes required.

\section{Materials and methods}

Data on the lice parasitising Mallard Anas platyrhynchos, Woodcock Scolopax rusticola, Collared Dove Streptopelia decaocto, Rook Corvus frugilegus and Hooded Crow Corvus corone cornix are presented in Table 1. These data were derived from a long-term faunistic survey carried out in Hungary and Romania. Most birds were shot, a few individuals of doves, rooks and crows were handled accidentally when recently hit by cars, poisoned, etc. Their plumage was visually searched for lice, with special attention to sites known to be preferred by lice. Lice seen were collected with forceps. Louse species with low prevalence (less than $10 \%$ of host individuals parasitised) were excluded from the present study. All lice were identified by the first author. Four of these distributions have already been published by us (Rózsa et al. 1996). Since these calculations were based on adult lice only and thus results were not comparable to those of others, we now redescribe the same distributions with the nymphs also included in the counts.

Hereafter the term 'louse subpopulation' is used to mean all the conspecific, hatched (nymphs and adults) louse individuals living on the same host individual. The following measures are applied. Prevalence (\%) is the proportion of hosts infested within the sample of hosts examined. The mean $(\overline{\mathrm{x}})$ of louse subpopulations is the average number of louse individuals per host individual including the zero values of louse-free hosts. The variance $\left(\mathrm{s}^{2}\right)$ of louse subpopulations also includes the louse-free hosts.

Hosts were pooled into 22 categories $(0,1,2, \ldots 20$, and $>20$ lice per individual). Categories with no observed bird (zero values, e.g. no Mallard was found to be infested by five individuals of Anaticola crassicornis) were also represented. The exponent $k$ of the negative binomial distribution was estimated by the maximum likelihood method and the expected frequencies were calculated as described by Bliss and Fisher (1953) and 
summarised by Krebs (1989). The expected frequency of the final category equalled 1 minus the sum of all the expected frequencies of previous categories. Pools with expected frequencies lower than 1 were lumped until the values equalled or exceeded 1. Expected frequencies of the negative binomial were not rounded to integers. The goodness of fit between the observed and expected frequencies was determined by $\chi^{2}$ tests (one-way classification, $\mathrm{df}=$ the number of categories -3 ).

Finally, the index of discrepancy (D) was calculated for our data set and also for those that could be reconstructed from the papers reviewed. Calculations were made by a simple program written in BASIC, following Poulin's (1993) definition. This index quantifies the disparity between observed and uniform distributions. Both $k$ and $\mathrm{D}$ describe the degree of aggregation ( $k$ indices decrease, D indices increase with increasing levels of aggregation).

An additional 12 statistical distributions of avian lice were obtained from Fowler and Miller (1984), Fowler and Williams (1985), Fowler and Price (1987), Fowler and Hodson (1988, 1991), Fowler and Shaw (1989), Clark at al. (1994), Lee and Clayton (1995) and Potti and Merino (1995). All of the distributions involved in the present paper include both the nymphal and the adult life stages of lice collected from fledged or adult birds. Louse egg data, lice of nestlings and distributions including more than one louse species were rejected. Unfortunately, the presentation of rough data is obviously self-contradictory in some of these papers. We accepted Fig. 2 of Fowler and Miller (1984), Fig. 1A of Fowler and Hodson (1988), Fig. 2 of Fowler and Hodson (1991) and Table 2 of Clark et al. (1994) as authentic sources of rough data for the calculation of discrepancy indices.

The estimation of the negative binomial exponent $k$ and the $\chi^{2}$ test of the goodness of fit between expected and observed frequencies is questionable in some of the studies reviewed. Authors prefer the simplest estimation of $k\left(k=\mathrm{x}^{2} /\left(\mathrm{s}^{2}-\overline{\mathrm{x}}\right)\right)$, even though this estimation gives misleading results and its use is strongly contradicted in case of the highly aggregated distributions (Southwood 1978, Krebs 1989) typical of most species of avian lice. Furthermore, categorisation is often unclear, infestation classes with zero observed frequencies (i.e. no birds observed) appear to be simply rejected in some cases. Classes with low expected frequencies $(<1)$ were not lumped in some studies, while too many classes were united in others (up to expected frequencies equalling 5 , instead of 1 , the value recommended for one-way classification). Using the convenient $\chi^{2}$ tests for two-way classification instead of one-way classification may be a further source of error. Test results may also be wrong because of miscalculation of the degrees of freedom. The degree of freedom must equal the number of frequency classes used minus three, since three statistics $(\mathrm{N}, \overline{\mathrm{x}}, k)$ have been used to create a theoretical distribu- tion from the observed data. Unfortunately, most of the widespread statistics programmes offer no help for these calculations. Therefore, future authors are strongly encouraged to take special care to provide both the rough data and the methods of pooling and calculation in an exact form.

Because Potti and Merino (1995) did not apply the negative binomial model, we estimated $k$ from their data $\left(k=\mathrm{x}^{2} /\left(\mathrm{s}^{2}-\overline{\mathrm{x}}\right)\right)$ without testing the goodness of fit. Furthermore, we were unable to test the fit of the model in the case of one species in our data set (Trinoton luridum), because the low number of infestation classes did not allow us to achieve a positive degree of freedom for the $\chi^{2}$ test.

Minimum sample sizes are estimated for negative binomial distribution models for each case study described and reviewed here. Calculations were made for $\pm 50 \%$ and for $\pm 10 \%$ precision using simplified equations $(\mathrm{n} \approx 16(1 / \overline{\mathrm{x}}+1 / k)$ and $\mathrm{n} \approx 400(1 / \overline{\mathrm{x}}+1 / k)$, respectively (Krebs 1989).

Bird species were classified either as colonial or territorial with respect to their sociality during the breeding season. This classification was based on Cramp and Simmons $(1983,1984)$, Cramp $(1985,1988)$ and Cramp and Perrins (1993, 1994a, 1994b). Twelve louse species of colonial birds and 15 species of territorial birds were used in the data set. Birds with facultative colonial breeding were not represented. The prevalence, mean, variance, $k$ and $\mathrm{D}$ values of lice of colonial host species were compared to those of non-colonial host species by means of Student t (parametric) and Mann-Whitney (nonparametric) tests.

The relationship between log mean and log variance of louse subpopulations was analysed by means of linear regression. Means and variances were $\log$ transformed to express the assumption that different louse species are equally likely to make the same proportional change in these measures. Log variance was a linear function of $\log$ mean (linear regression, $r=0.8552$, $\mathrm{F}=68.069$, d.f. $=26, \mathrm{P}<0.0001)$. The linear regression line $\mathrm{Y}=1.81 \mathrm{X}+0.85$ was used to calculate predicted values of $\log$ variance. Predicted log variances were subtracted from the observed values to obtain log-residuals.

All statistical tests are two-tailed. Computations were carried out by InStat 2.01. Host sample size - a factor known to influence some of these measures (Gregory and Woolhouse 1993, Poulin 1993, 1996) - did not differ between the two groups (Student's $t=0.2450$, d.f. $=25, P>0.80$ ). Similarly, host body size - which may also correlate with ectoparasite subpopulation size (Poiani 1995) - did not differ significantly between the two groups (body size data obtained from Dunning 1993; Mann-Whitney U-statistic $=69.0, \mathrm{~N}_{1}=12, \mathrm{~N}_{2}=$ $15, \mathrm{P}>0.32$ ). From these points of view, the present comparisons between the distribution measures of lice of colonial versus territorial hosts are unbiased. 


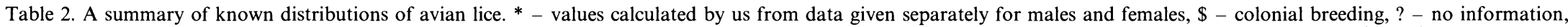
!! - do not fit the negative binomial at $\mathrm{P}<0.05$, ! - do not fit the negative binomial at $\mathrm{P}<0.10$, $\S$ - without testing the goodness of fit to the negative binomial

\begin{tabular}{|c|c|c|c|c|c|c|c|c|c|c|}
\hline Source & Host species & $\underset{\text { host }}{\mathrm{N}}$ & Louse species & $\begin{array}{c}\text { Prev. } \\
\%\end{array}$ & $\overline{\mathrm{x}}$ & Var. $\left(s^{2}\right)$ & $k$ & $\begin{array}{l}\mathrm{D} \text { of } \\
\text { Poulin }\end{array}$ & $\begin{array}{c}\text { Min. } \\
\text { sample } \\
\text { size } \\
\pm 10 \%\end{array}$ & $\begin{array}{c}\text { Min. } \\
\text { sample } \\
\text { size } \\
\pm 50 \%\end{array}$ \\
\hline Fowler and Miller 1984 & Hydrobates pelagicus $\$$ & 240 & Halipeurus pelagicus & 97.5 & 5.75 & 13.48 & 4.27 & 0.359 & 163 & 7 \\
\hline Fowler and Miller 1984 & Fulmarus glacialis \$ & 35 & Perineus nigrolimbatus & 80 & 2.74 & 8.67 & 1.27 & 0.568 & 461 & 18 \\
\hline Fowler and Williams 1995 & Emberiza schoeniclus & 213 & Philopterus docophorulus & 21.6 & 0.75 & 5.2 & 0.13 & ? & 3610 & 144 \\
\hline Fowler and Williams 1995 & Emberiza schoeniclus & 111 & Philopterus docophorulus & 24.3 & 1.91 & 36.5 & 0.116 & ? & 3658 & 146 \\
\hline Fowler and Price 1987 & Oceanites oceanicus \$ & 102 & Philoceanus robertsi & ? & 6.6 & 34.8 & 1.56 & ? & 317 & 13 \\
\hline Fowler and Hodson 1988 & Oceanodroma leucorhoa \$ & 100 & Halipeurus pelagicus & 61 & 1.4 & 3.04 & 1.121 & 0.597 & 643 & 26 \\
\hline Fowler and Show 1969 & Puffinus $p$. puffinus $\$$ & 230 & Trabeculus aviator & 99.5 & 28.7 & 368.7 & 2.42 & ? & 179 & 7 \\
\hline Fowler and Show 1969 & Puffinus p. puffinus $\$$ & 230 & Halipeurus diversus & 99.5 & 24.2 & 316.8 & 2.00 & ? & 217 & 9 \\
\hline Fowler and Hodson 1991 & Cinclus cinclus & 50 & Philopterus cincli & 54.0 & 1.6 & 9.76 & 0.314 & 0.743 & 1524 & 61 \\
\hline Clark et al. 1994 & Delichon urbica \$ & 161 & Bruelia gracilis & 49 & 3.20 & 45.35 & 0.24 & 0.766 & 1792 & 72 \\
\hline Lee and Clayton 1994 & Apus apus \$ & 87 & Dennyus hirundinis & 67.8 & 1.9 & 5.2 & 1.1 & 0.581 & 574 & 23 \\
\hline Potti and Merino 1995* & Ficedula hypoleuca & 462 & Docophorulus capillatus & 23.6 & 0.66 & 4.82 & $0.105 \S$ & 0.901 & 4416 & 177 \\
\hline Present paper & Anas platyrhynchos & 72 & Anaticola crassicornis & 54.2 & 37.4 & 977306.24 & 0.31 ! & 0.939 & 1301 & 52 \\
\hline Present paper & Anas platyrhynchos & 72 & Anatoecus dentatus & 20.8 & 3.49 & 181.71 & $0.07 !$ & 0.916 & 5829 & 233 \\
\hline Present paper & Anas platyrhynchos & 72 & Anatoecus icterodes & 16.7 & 8.18 & 4180.92 & 0.07 & 0.965 & 5763 & 231 \\
\hline Present paper & Anas platyrhynchos & 72 & Trinoton querquedulae & 12.5 & 0.96 & 27.98 & 0.05 & 0.943 & 8417 & 337 \\
\hline Present paper & Anas platyrhynchos & 72 . & Trinoton luridum & 12.5 & 0.26 & 0.62 & $0.11 \S$ & 0.895 & 5175 & 207 \\
\hline Present paper & Scolopax rusticola & 102 & Cummingsiella aurea & 34.3 & 7.75 & 901.20 & $0.14 ! !$ & 0.887 & 2909 & 116 \\
\hline Present paper & Scolopax rusticola & 102 & Rhynonirmus helvolus & 19.6 & 8.79 & 4610.41 & 0.07 & 0.956 & 5760 & 230 \\
\hline Present paper & Streptopelia decacoto & 111 & Columbicola columbae bacillus & 50.5 & 3.75 & 45.29 & $0.29 !$ & 0.734 & 1486 & 59 \\
\hline Present paper & Streptopelia decacoto & 111 & Coloceras sofioticus & 16.2 & 0.75 & 13.10 & 0.08 & 0.925 & 5533 & 221 \\
\hline Present paper & Corvus frugilegus $\$$ & 37 & Myrsidea isostoma & 70.27 & 15.46 & 1151.24 & 0.51 & 0.722 & 810 & 32 \\
\hline Present paper & Corvus frugilegus $\$$ & 37 & Philopterus atratus & 64.86 & 15.11 & 1075.84 & 0.40 & 0.773 & 1026 & 41 \\
\hline Present paper & Corvus frugilegus $\$$ & 37 & Brueelia tasniamae & 45.95 & 21.27 & 1916.69 & 0.23 & 0.759 & 1758 & 70 \\
\hline Present paper & Corvus frugilegus $\$$ & 37 & Allocolpocephalum fregili & 24.32 & 1.03 & 7.08 & 0.13 & 0.848 & 3465 & 139 \\
\hline Present paper & Corvus corone cornix & 89 & Myrsidea cornicis & 32.58 & 3.85 & 147.87 & $0.14 ! !$ & 0.848 & 2961 & 118 \\
\hline Present paper & Corvus corone cornix & 89 & Philopterus ocellatus & 43.82 & 4.90 & 94.67 & $0.21 ! !$ & 0.771 & 1986 & 79 \\
\hline
\end{tabular}


Table 3. $\chi^{2}$ tests for the goodness of fit of the observed distributions to the expected frequencies of the negative binomial model. The distributions with low P-values do not fit the theoretical model.

\begin{tabular}{lcrrc}
\hline Species & $k$ & $\chi^{2}$ & d.f. & $\mathrm{P}$ \\
\hline Anaticola crassicornis & 0.31 & 21.698 & 13 & $>0.06$ \\
Anatoecus dentatus & 0.07 & 11.600 & 6 & $>0.07$ \\
Anatoecus icterodes & 0.07 & 6.450 & 5 & $>0.26$ \\
Trinoton querquedulae & 0.05 & 0.225 & 3 & $>0.97$ \\
Cummingsiella aurea & 0.14 & 23.602 & 12 & $<0.03$ \\
Rhynonirmus helvolus & 0.07 & 9.384 & 8 & $>0.31$ \\
Columbicola columbae & 0.29 & 21.752 & 14 & $>0.08$ \\
$\quad$ bacillus & & & & \\
Coloceras sofioticus & 0.08 & 2.679 & 5 & $>0.74$ \\
Myrsidea isostoma & 0.51 & 10.091 & 12 & $>0.60$ \\
Philopterus atratus & 0.40 & 12.417 & 11 & $>0.33$ \\
Brueelia tasniamae & 0.23 & 13.961 & 9 & $>0.12$ \\
Allocolpocephalum fregili & 0.13 & 1.062 & 3 & $>0.78$ \\
Myrsidea cornicis & 0.14 & 19.765 & 11 & $<0.05$ \\
Philopterus ocellatus & 0.21 & 28.520 & 13 & $<0.01$ \\
\hline
\end{tabular}

\section{Results}

Data characterising the 27 known louse-bird distributions are summarised in Table 2. The variance of louse subpopulation size exceeded the mean in all cases, indicating an aggregated distribution pattern. One distribution out of 11 taken from the literature differed significantly (at $\mathrm{P}<0.05$ ) from the negative binomial model and the fit of one distribution was not tested. Similarly, three out of 14 distributions in our own data set differed significantly from the negative binomial model ( $\mathrm{P}<0.05$, see Table 3$)$, while the fit of the distribution of Trinoton luridum was impossible to test because of the small number of categories.

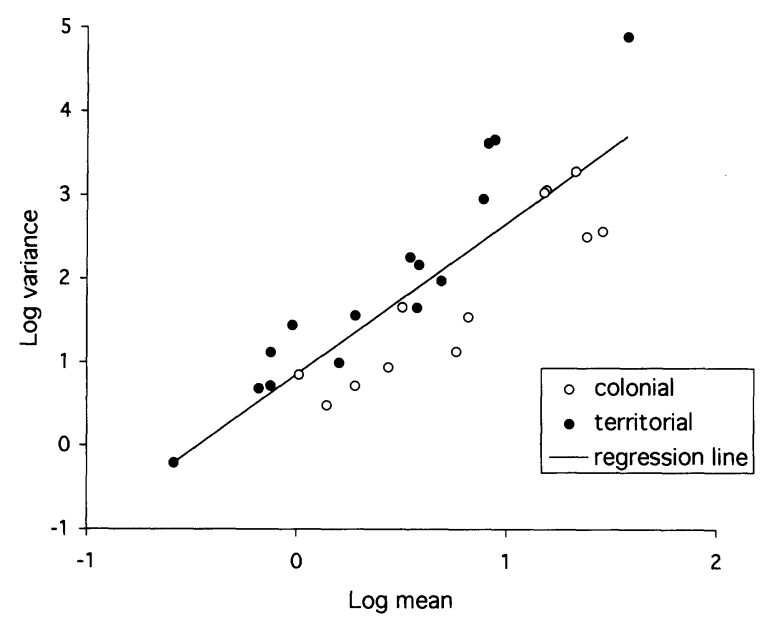

Fig. 1. Log variance of louse subpopulation size is a linear function of $\log$ mean of subpopulation size. Lice of territorial hosts tend to form more variable, while those of colonial birds tend to form less variable subpopulations than those predicted by the regression line.
The mean $(\overline{\mathrm{x}})$ and variance $\left(\mathrm{s}^{2}\right)$ of the louse subpopulations of colonial hosts did not differ significantly from those of territorial species (Student's $\mathrm{t}=1.3360$, d.f. $=$ 25, $\mathrm{P}>0.19$, Mann-Whitney U-statistic $=86.5, \mathrm{~N}_{1}=12$, $\mathrm{N}_{2}=15, \mathrm{P}>0.86$ respectively). However, log-residuals were significantly lower for the distributions of lice of colonial birds than those of territorial breeders (MannWhitney U-statistic $=6.0, \mathrm{~N}_{1}=12, \mathrm{~N}_{2}=15, \mathrm{P}<0.0001$, Fig. 1).

Louse prevalence $(\%)$ was significantly higher in colonial hosts than in territorial ones (Mann-Whitney Ustatistic $\left.=12.0, \mathrm{~N}_{1}=11, \mathrm{~N}_{2}=15, \mathrm{P}<0.0001\right)$. Values of the negative binomial exponent $k$ were significantly higher, while the index of discrepancy (D) was significantly lower in colonial hosts than in territorial ones (Mann-Whitney U-statistic $=19.0, \mathrm{~N}_{1}=12, \quad \mathrm{~N}_{2}=15$, $P<0.0002$; Mann-Whitney U-statistic $=10.5, \quad \mathrm{~N}_{1}=9$, $\mathrm{N}_{2}=13, \mathrm{P}<0.001$, respectively for $k$ and $\left.\mathrm{D}\right)$ indicating less aggregated distributions in the former case.

\section{Discussion}

Aggregated distributions are familiar to all those studying parasite ecology. However, the finding that some distributions do not fit the negative binomial model is clearly unusual. In all cases, the variance exceeded the mean of the distribution, confirming the aggregated nature of distributions. Highly significant differences between the log-residuals of lice of colonial versus territorial birds indicate more variable size of louse subpopulations in territorial than colonial birds (Fig. 1).

The significant difference between louse prevalences of colonial and territorial birds is somewhat surprising as this measure often appears to be an oversimplified and less informative one. It has to be noted, however, that all species with a prevalence less than $10 \%$ were excluded from the present data set, including several rare louse species of colonial hosts.

The negative binomial exponent $k$ exhibited values correlating with host social system. However, as some distributions did not conform to the negative binomial model, and the methods of calculating $k$ are diverse and often impossible to reproduce, there is room for some scepticism when interpreting this pattern.

The index of discrepancy (D) also correlates with host social system. Although the introduction of this index has provoked some debate (Ploeger 1994, 1996, Poulin 1995, 1996), we can recommend its use in future studies since it has the major advantages of being free from mathematical preconceptions and also of undefined steps of pooling.

Minimum sample size requirements to assess the mean of louse subpopulations are surprisingly high, particularly in case of territorial host species. Sample size requirements for a $\pm 50 \%$ precision were met in only 14 out of the 27 cases and for a $\pm 10 \%$ precision 
in only three cases. Thus, the means and variances published by previous authors and in the present paper are mostly of an indicative nature, referring to actual samples, but not necessarily representing the populations from which the samples were derived. Surprisingly, this may also be true for the values of the exponent $k$ estimated by previous authors, since $k$ was estimated by an equation that incorporated the mean.

A further shortcoming of our data set is that it is not an unbiased sample of birds or lice in general. Thus passeriform species are under-represented $\left(\chi^{2}=16.647\right.$, d.f. $=1, \mathrm{P}<0.0001$ ), while procellariid seabirds are over-represented $\left(\chi^{2}=80.366\right.$, d.f. $\left.=1, \mathrm{P}<0.0001\right)$ in this sample relative to their proportion in the global avifauna (data obtained from Sibley and Monroe 1990). Comparative methods that control for phylogeny cannot be used in this case, since distribution measures are not species characters of either birds, or lice. These measures are characters of bird-louse interactions: species associations whose phylogeny is unknown. Furthermore, since certain louse species are inherently rare (Rózsa 1993), and these species are excluded from population studies, a further bias may appear because of the lack of rare species. Thus the only claims we can make are that virtually all of those distributions have been reviewed here that conformed to our criteria, and that the number of appropriate distributions was increased considerably by those published in the present paper.

In spite of all these efforts, our sample of lice and birds is still not unbiased and minimum sample size requirements were not met in certain cases. The reason for this is the aggregated nature of louse distributions, particularly in case of lice harboured by territorial, solitary birds. This feature may make it technically impossible to achieve appropriate sample sizes in the field. In spite of all these problems, the available data do indicate that the distribution of lice is more aggregated, therefore the prevalence is lower and the variance of louse subpopulation size (relative to mean) is higher, in territorial than in colonial birds. Louse subpopulations do not tend to be larger on colonial hosts than on territorial birds, presumably due to the similarity of antiparasite defence mechanisms in the two groups of birds. Thus, the size of louse populations parasitising colonial host populations do not exceed those on non-colonial host populations. In this particular sense, colonial hosts do not pay a higher price for being social.

This pattern is significant from an evolutionary point of view. The finding that avian lice are not more abundant, but more equally distributed among colonial hosts yields the prediction that selection pressure exerted by lice upon their host population should be lower in colonial birds, since the disadvantages of parasitism are distributed more equally among the members of the population.
Acknowledgements - We are greatly indebted to all those people who helped us in the collection of lice throughout three decades. We thank Bernie Zonfrillo for providing papers unavailable in Hungary, Jenö Reiczigel for advice on mathematics and our referee for valuable comments. LR was supported by the grant OTKA F 016792.

\section{References}

Bliss, C. I. and Fisher, R. A. 1953. Fitting the negative binomial distribution to biological data. - Biometrics 9: $176-200$.

Brown, C. R. and Brown, M. B. 1986. Ectoparasitism as a cost of coloniality in cliff swallows (Hirundo pyrrhonota). Ecology 67: 1206-1218.

Chapman, B. R. and George, J. E. 1991. The effects of ectoparasites on cliff swallow growth and survival. - In: Loye, J. E. and Zuk, M. (eds.). Bird-Parasite Interactions: Ecology, Evolution and Behaviour. Oxford Univ. Press, Oxford, pp. 69-92.

Clark, F., Farrel, J. and Hill, L. A. 1994. A study of a population of the house martin (Delichon urbica (L.)) feather louse Brüelia gracilis (Mallophaga: Ischnocera) in Lincolnshire, UK. - Entomologist 113: 198-204.

Cramp, S. (ed.) 1985, 1988. Handbook of the Birds of Europe, the Middle East and North-Africa: the Birds of the Western Palearctic. Vols. IV and V. - Oxford Univ. Press, Oxford.

- and Perrins, C. M. (eds.) 1993, 1994a, 1994b. Handbook of the Birds of Europe, the Middle East and North-Africa: the Birds of the Western Palearctic. Vols. VII, VIII and IX. - Oxford Univ. Press, Oxford.

- and Simmons, K. E. L. (eds.) 1983, 1984. Handbook of the Birds of Europe, the Middle East and North-Africa: the Birds of the Western Palearctic. Vols. I and III. - Oxford Univ. Press, Oxford.

Crofton, H. D. 1971. A quantitative approach to parasitism. Parasitology 62: 179-193.

Duffy, D. C. 1991. Ants, ticks and nesting seabirds: dynamic interactions? - In: Loye, J. E. and Zuk, M (eds.). Bird-Parasite Interactions: Ecology, Evolution and Behaviour. Oxford Univ. Press, Oxford, pp. 242-257.

Dunning, J. B. 1993. CRC handbook of avian body masses. CRC Press, Boca Raton, USA.

Fowler, J. A. and Hodson, D. 1988. The Mallophaga of Leach's Petrels Oceanodroma leucorhoa from North Rona, Scotland. - Seabird 11: 47-49.

- and Hodson, D. P. 1991. Feather lice (Mallophaga) of the Dipper Cinclus cinclus in Central Wales. - Ringing \& Migration 12: 43-45.

- and Miller, C. J. 1984. Non-haematophagous ectoparasite populations of Procellariiform birds in Shetland, Scotland. - Seabird 7: 23-30.

- and Price, R. A. 1987. A comparative study of the Ischnoceran Mallophaga of the Wilson's Petrel Oceanites oceanicus and British Storm Petrel Hydrobates pelagicus. Seabird 10: 43-49.

- and Shaw, G. J. 1989. The Mallophaga of Manx Shearwaters Puffinus p. puffinus from Ynys Enlli, Wales. - Seabird 12: $14-19$.

- and Williams, L. R. 1985. Population dynamics of Mallophaga and Acari on reed buntings occupying a communal winter roost. - Ecol. Entomol. 10: 377-383.

Gregory, R. D. and Woolhouse, M. E. J. 1993. Quantification of parasite aggregation: a simulation study. - Acta Tropica 54: $131-139$.

Krebs, C. J. 1989. Ecological methodology. - Harper and Row, NY.

Lee, P. L. M. and Clayton, D. H. 1995. Population biology of swift (Apus apus) ectoparasites in relation to host reproductive success. - Ecol. Entomol. 20: 43-50. 
Loye, J. E. and Caroll, S. P. 1991. Nest ectoparasite abundance and cliff swallow colony site selection, nestling development, and departure time. - In: Loye, J. E. and Zuk, M. (eds.). Bird-Parasite Interactions: Ecology, Evolution and Behaviour. Oxford Univ. Press, Oxford, pp. 222-241.

Møller, A. P. 1987. Advantages and disadvantages of coloniality in the swallow (Hirundorustica). - Anim. Behav. 35: 819-832.

Ploeger, H. W. 1994. Comments on Poulin, R. The disparity between observed and uniform distributions: a new look at parasite aggregation. - Int. J. Parasitol. 24: 919-920.

- 1996. More "misconceptions" about the measurement of aggregation. - Int. J. Parasitol. 26: 223-226.

Poiani, A. 1992. Ectoparasitism as a possible cost of social life: a comparative analysis using Australian passerines (Passeriformes). - Oecologia 92: 429-441.

Potti, J. and Merino, S. 1995. Louse loads of pied flycatchers: effects of host's sex, age, condition and relatedness. - J. Avian Biol. 26: 203-208.

Poulin, R. 1991. Group-living and infestation by ectoparasites in passerines. - Condor 93: 418-423.

- 1993. The disparity between observed and uniform distributions: a new look at parasite aggregation. - Int. J. Parasitol. 23: 937-944.
- 1995. Misconceptions about the measurement of aggregation: a reply to Ploeger. - Int. J. Parasitol. 25: 863864.

- 1996. Measuring parasite aggregation: defending the index of discrepancy. - Int. J. Parasitol. 26: 227-229.

Rózsa, L. 1993. Speciation patterns of ectoparasites and "straggling" lice. - Int. J. Parasitol. 23: 859-864.

- , Rékási, J. and Reiczigel, J. 1996. Relationship of host coloniality to the population ecology of avian lice (Insecta: Phthiraptera). - J. Anim. Ecol. 65: 242-248.

Shields, W .M. and Crook, J. 1987. Barn swallow coloniality: a net cost for group breeding in the Adirondacks? Ecology 68: 1373-1386.

Sibley, C. G and Monroe, B. L. 1990. Distribution and taxonomy of birds of the world. - Yale University Press, New Haven and London.

Southwood, T. R. E. 1978. Ecological methods with particular reference to the study of insect populations. - Chapman and Hall, London.

(Received 17 June 1996, revised 7 November 1996, accepted 27 November 1996.) 